\title{
Articles
}

\section{$\vartheta$ Comparison of carvedilol and metoprolol on clinical outcomes in patients with chronic heart failure in the Carvedilol Or Metoprolol European Trial (COMET): randomised controlled trial}

\author{
Philip A Poole-Wilson, Karl Swedberg, John G F Cleland, Andrea Di Lenarda, Peter Hanrath, Michel Komajda, Jacobus Lubsen, \\ Beatrix Lutiger, Marco Metra, Willem J Remme, Christian Torp-Pedersen, Armin Scherhag, Allan Skene, for the COMET \\ investigators*
}

\begin{abstract}
Summary
Background $\beta$ blockers reduce mortality in patients who have chronic heart failure, systolic dysfunction, and are on background treatment with diuretics and angiotensin-converting enzyme inhibitors. We aimed to compare the effects of carvedilol and metoprolol on clinical outcome.

Methods In a multicentre, double-blind, and randomised parallel group trial, we assigned 1511 patients with chronic heart failure to treatment with carvedilol (target dose $25 \mathrm{mg}$ twice daily) and 1518 to metoprolol (metoprolol tartrate, target dose $50 \mathrm{mg}$ twice daily). Patients were required to have chronic heart failure (NYHA II-IV), previous admission for a cardiovascular reason, an ejection fraction of less than 0.35 , and to have been treated optimally with diuretics and angiotensinconverting enzyme inhibitors unless not tolerated. The primary endpoints were all-cause mortality and the composite endpoint of all-cause mortality or all-cause admission. Analysis was done by intention to treat.
\end{abstract}

Findings The mean study duration was 58 months (SD 6). The mean ejection fraction was $0.26(0.07)$ and the mean age 62 years (11). The all-cause mortality was 34\% (512 of 1511) for carvedilol and 40\% (600 of 1518) for metoprolol (hazard ratio 0.83 [95\% $\mathrm{Cl} 0.74-0.93$ ], $\mathrm{p}=0.0017$ ). The reduction of allcause mortality was consistent across predefined subgroups. The composite endpoint of mortality or all-cause admission occurred in 1116 (74\%) of 1511 on carvedilol and in 1160 (76\%) of 1518 on metoprolol (0.94 [0.86-1.02], $p=0.122)$. Incidence of side-effects and drug withdrawals did not differ by much between the two study groups.

Interpretation Our results suggest that carvedilol extends survival compared with metoprolol.

Lancet 2003; 362: 7-13

See Commentary page 2

*Members listed at end of report

National Heart and Lung Institute, Imperial College London, UK (Prof P A Poole-Wilson MD); Department of Medicine, Sahlgrenska University Hospital/Östra, Göteborg, Sweden (Prof K Swedberg MD); Department of Cardiology, University of Hull, Kingston upon Hull, UK (Prof J G F Cleland MD); Department of Cardiology, Ospedale di Cattinara, Trieste, Italy (A Di Lenarda MD); Medizinische Klinik 1, University Hospital, Aachen, Germany (Prof P Hanrath MD); Department of Cardiology, La Pitié-Salpétrière Hospital, Paris, France (Prof M Komajda MD); SOCAR Research SA, Nyon, Switzerland and Erasmus Medical Centre, Rotterdam, Netherlands (Prof J Lubsen MD); F Hoffmann La Roche, Basel, Switzerland (B Lutiger MSc, A Scherhag MD); Cattedra di Cardiologia, Università di Brescia, Italy (M Metra MD); Sticares Cardiovascular Research Foundation, Rhoon, Netherlands (Prof W J Remme MD); Department of Cardiology, Bispebjerg University Hospital, Copenhagen, Denmark (Prof C Torp-Pedersen MD); Nottingham Clinical Research Group (NCRG), Nottingham, UK (A Skene PhD)

Correspondence to: Prof Philip A Poole-Wilson, Cardiac Medicine, Faculty of Medicine, Imperial College London, London SW3 6LY, UK (e-mail: p.poole-wilson@imperial.ac.uk)

\section{Introduction}

Chronic heart failure is common, ${ }^{1}$ readily diagnosed, the cause of disabling symptoms, has a poor prognosis, and consumes about $2 \%$ of the total health budget in developed countries.

Therapeutic strategies for chronic heart failure are based on the notions of restriction of fluid retention and inhibition of activation of neurohumoral systems, notably the reninangiotensin pathway and the sympathetic system. Guidelines recommend a combination of diuretics, angiotensinconverting enzyme (ACE) inhibitors, and $\beta$ blockers with or without digoxin as a basis for treatment. ${ }^{2}$ Aldosterone inhibitors are often used in patients with more severe heart failure. Results of large clinical trials have shown that although treatment with ACE inhibitors lessens admissions and improves survival, ${ }^{3}$ morbidity and mortality remain high. Addition of a $\beta$ blocker further reduces mortality ${ }^{4-8}$ and has various effects on symptoms. ${ }^{9-11}$ Many mechanisms for the benefits of these drugs have been put forward.

$\beta$ blockers have different pharmacological profiles, for example adrenergic receptor selectivity and the presence of ancillary properties. Metoprolol and bisoprolol have a high specificity for the $\beta-1$ adrenergic receptor. Carvedilol blocks $\beta-1, \beta-2$, and $\alpha-1$ adrenergic receptors. ${ }^{12}$ Bucindolol did not have a mortality benefit in chronic heart failure. ${ }^{13}$ Results of a meta-analysis ${ }^{14}$ suggested that carvedilol was associated with a greater increase in left-ventricular ejection fraction than metoprolol. Several other small studies ${ }^{12,15-17}$ have suggested that carvedilol is more effective than metoprolol in terms of remodelling and central haemodynamics, but the two drugs are similar in their effect on quality of life $\mathrm{f}^{10}$ or peak oxygen consumption. ${ }^{15,16}$ Carvedilol has several other effects that might be advantageous in heart failure. It increases insulin sensitivity whereas metoprolol has the opposite effect. ${ }^{18}$ The antioxidant action of carvedilo ${ }^{19}$ might improve endothelial dysfunction and prevent apoptosis, mechanisms that could be important in the progression of chronic heart failure. ${ }^{20}$

We designed the Carvedilol Or Metoprolol European Trial (COMET) to compare directly the effects of carvedilol and metoprolol on mortality and morbidity in patients with mild to severe chronic heart failure.

\section{Methods \\ Design}

COMET was a multicentre, randomised, double-blind, parallel-group trial to compare the effect on mortality and morbidity of carvedilol and metoprolol in patients with chronic heart failure. A detailed description of the study design has been published, including the method of randomisation, monitoring, and follow-up. ${ }^{21}$ The study was done in 15 European countries, involving 341 centres, of which 317 contributed at least one patient. During the trial one centre was withdrawn from the study because of irregularities. Recruitment began on Dec 1, 1996, and ended on Jan 15, 1999. Follow-up for mortality and morbidity was concluded on Nov 15, 2002. 


\section{Patients}

Eligible patients were men or women with symptomatic chronic heart failure (New York Heart Association [NYHA] class II-IV), at least one cardiovascular admission during the previous 2 years, on stable heart failure treatment with ACE inhibitors for at least 4 weeks unless contraindicated, and on treatment with diuretics $(\geqslant 40 \mathrm{mg}$ of frusemide or equivalent) for at least 2 weeks. Digitalis, angiotensin II inhibitors, or other vasodilators could be used at the discretion of the investigators. Left-ventricular ejection fraction had to be 0.35 or lower measured within the previous 3 months by echocardiography or radionuclide ventriculography. If the ejection fraction was not determined, a left-ventricular end diastolic diameter of greater than $6.0 \mathrm{~cm}$ and a fractional shortening of less than $20 \%$ as measured by echocardiography could qualify patients.

Major exclusion criteria were a recent change of treatment-defined as the introduction of a new class of drug for heart failure or treatment with oral $\beta$-adrenergic or $\alpha$-adrenergic receptor blockers within the 2 weeks before randomisation-requirement for intravenous inotropic therapy, current treatment with calcium channel blockers (of the diltiazem or verapamil class), amiodarone (>200 mg per day) or class-I antiarrhythmic drugs, or administration of any investigational drug within the preceding 30 days. We excluded patients with unstable angina, myocardial infarction, or coronary revascularisation or stroke within the previous 2 months. Other exclusion criteria were uncontrolled hypertension (blood pressure systolic $>170$ $\mathrm{mm} \mathrm{Hg}$ or diastolic $>105 \mathrm{~mm} \mathrm{Hg}$ ), haemodynamically significant valvular disease, symptomatic and sustained ventricular arrhythmias within the past 2 months not adequately treated with antiarrhythmic drugs or implantation of an automatic defibrillator, pregnancy, women with childbearing potential on inadequate contraception, known drug or alcohol misuse, poor compliance with treatment or any other serious systemic disease that might complicate management and reduce life expectancy.

We also excluded patients if there was a contraindication to use of $\beta$ blockers, such as resting heart rate of fewer than 60 beats per min, sick sinus syndrome, bifascicular block, second or third degree atrioventricular block unless treated with a pacemaker, sitting systolic blood pressure of less than $85 \mathrm{~mm} \mathrm{Hg}$, history of asthma or chronic obstructive pulmonary disease, peripheral arterial disease with symptoms at rest, or unstable insulin-dependent diabetes mellitus.

The study conformed to good clinical practice guidelines and followed the recommendations of the Declaration of Helsinki. The protocol was approved by the relevant and local ethics review boards. Written informed consent was obtained from all patients before enrolment.

\section{Procedures}

At randomisation, we assigned the 3029 eligible patients to receive either $3.125 \mathrm{mg}$ carvedilol twice daily or $5 \mathrm{mg}$ metoprolol tartrate twice daily. Randomisation was double blind and used the method of permuted blocks by centre. Investigators at each sites were supplied with numbered treatment kits and instructed to take the lowest numbered kit available for each new patient. Each kit contained sufficient drugs to allow complete flexibility of treatment. Patients entered initially a titration phase followed by a maintenance period.

During the titration phase the dose of each $\beta$ blocker was increased to the target dose of carvedilol $(25 \mathrm{mg}$ twice daily) or metoprolol (50 mg twice daily) every 2 weeks according to the following schedules: $6.25 \mathrm{mg}$ twice daily, $12.5 \mathrm{mg}$ twice daily, and $25 \mathrm{mg}$ twice daily for carvedilol, and $12.5 \mathrm{mg}$ twice daily, $25 \mathrm{mg}$ twice daily, and $50 \mathrm{mg}$ twice daily for metoprolol. The investigator could modify the dose regimen. If a patient did not tolerate an increase of dose, a temporary decrease in dose was allowed. Investigators were encouraged to adjust the dose of diuretics and ACE inhibitors to increase the dose of the $\beta$ blocker again towards the target dose. Subsequently during the maintenance phase all patients were assessed every 4 months until the end of the study. Patients undergoing heart transplantation remained in the study and were followed up in a manner identical to other patients.

Safety was monitored by an independent data and safety monitoring board. Adverse and serious adverse events were reported to the study data centre. All reports of adverse events were included irrespective of whether the investigators thought they had been caused by the treatment. Adverse events that were fatal or lifethreatening, required or extended admission, or resulted in persistent or significant disability or incapacity were labelled serious. All adverse events were coded, blinded to treatment group, by a validated and established dictionary that classifies events by major body systems. This procedure identifies cardiovascular events.

All fatal events were adjudicated by the endpoint committee masked to treatment status. We assigned mode of death to one of five categories: sudden death, circulatory failure, stroke, other cardiovascular death, and noncardiovascular death. Deaths that could not be classified because of insufficient information were deemed cardiovascular.

\section{Statistical analysis}

The study was planned as an event-driven parallel-group survival study to compare carvedilol and metoprolol with respect to all-cause mortality. In May, 2000, the steering committee, who had no knowledge of the interim results or treatment assignments, decided to add the composite endpoint of all-cause mortality or all-cause admission as a second primary endpoint. This endpoint had previously been the first secondary endpoint specified by the protocol. The change was made in recognition of the importance of admission in this population and to ensure that COMET had primary endpoints identical to those used in the MERIT-HF study. ${ }^{6}$

With the introduction of the second primary endpoint, we recalculated the required number of deaths. Although a composite endpoint had been introduced it remained our intention that the study be adequately powered to detect a

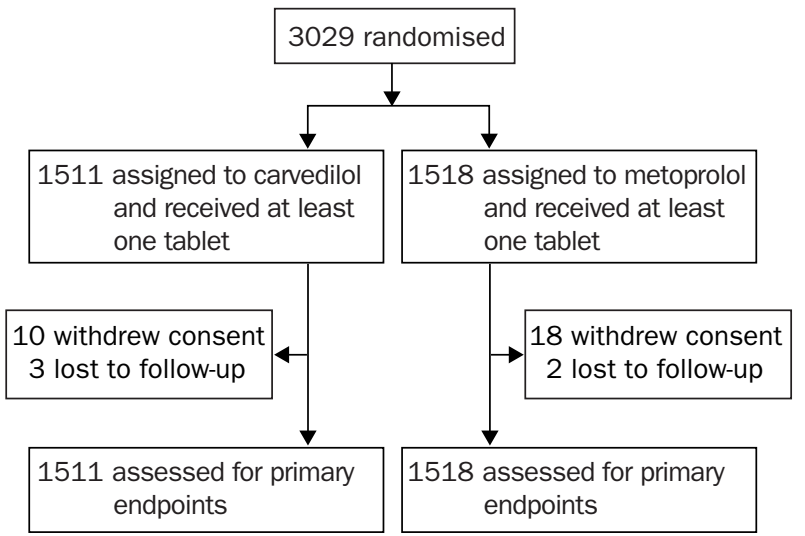

Figure 1: Trial profile 


\begin{tabular}{|c|c|c|}
\hline & $\begin{array}{l}\text { Carvedilol } \\
(n=1511)\end{array}$ & $\begin{array}{l}\text { Metoprolol } \\
(n=1518)\end{array}$ \\
\hline Age (years) & $61 \cdot 6(11 \cdot 3)$ & $62 \cdot 3(11 \cdot 4)$ \\
\hline Male sex & 1200 (79\%) & 1217 (80\%) \\
\hline White & 1494 (99\%) & 1504 (99\%) \\
\hline Body-mass index $\left(\mathrm{kg} / \mathrm{m}^{2}\right)$ & $26.9(4.5)$ & $26 \cdot 8(4 \cdot 4)$ \\
\hline Systolic blood pressure (mm Hg) & $126(19 \cdot 3)$ & $126(19 \cdot 7)$ \\
\hline Diastolic blood pressure (mm Hg) & $77(11 \cdot 0)$ & $77(10 \cdot 9)$ \\
\hline Heart rate (beats per minute) & $81(13 \cdot 2)$ & $81(13 \cdot 6)$ \\
\hline \multicolumn{3}{|l|}{ NYHA class } \\
\hline II & $730(48 \%)$ & $736(49 \%)$ \\
\hline III & $732(48 \%)$ & $716(47 \%)$ \\
\hline IV & $49(3 \%)$ & $66(4 \%)$ \\
\hline $\begin{array}{l}\text { Duration congestive heart failure } \\
\text { (months) }\end{array}$ & $42 \cdot 6(51 \cdot 3)$ & $42 \cdot 2(55 \cdot 9)$ \\
\hline \multicolumn{3}{|l|}{ Cause* } \\
\hline Ischaemic heart disease & $776(51 \%)$ & $815(54 \%)$ \\
\hline Hypertension & $270(18 \%)$ & $267(18 \%)$ \\
\hline Dilated cardiomyopathy & $667(44 \%)$ & $663(44 \%)$ \\
\hline Previous valve surgery & $43(3 \%)$ & $32(2 \%)$ \\
\hline Left-ventricular ejection fraction & $0.26(0.07)$ & $0.26(0.07)$ \\
\hline NT-proBNP $(\mu \mathrm{g} / \mathrm{L})$ & $1298(588-2792$ & $1185(508-2670$ \\
\hline Previous myocardial infarction & $626(41 \%)$ & $606(40 \%)$ \\
\hline CAD (confirmed by angiography) & $550(36 \%)$ & $580(38 \%)$ \\
\hline Current angina & $320(21 \%)$ & 331 (22\%) \\
\hline Previous angioplasty & $122(8 \%)$ & $124(8 \%)$ \\
\hline Previous CABG & $233(15 \%)$ & $282(19 \%)$ \\
\hline Hypertension & $561(37 \%)$ & $540(36 \%)$ \\
\hline Diabetes & $360(24 \%)$ & $370(24 \%)$ \\
\hline Stroke & $106(7 \%)$ & $108(7 \%)$ \\
\hline \multicolumn{3}{|l|}{ Electrocardiographic findings* } \\
\hline Sinus rhythm & $1124(74 \%)$ & $1135(75 \%)$ \\
\hline Atrial fibrillation/flutter & 309 (21\%) & 291 (19\%) \\
\hline Paced rhythm & $90(6 \%)$ & $108(7 \%)$ \\
\hline LBBB & $88(6 \%)$ & $79(5 \%)$ \\
\hline \multicolumn{3}{|l|}{ Concomitant drugs at randomisation } \\
\hline Diureticst & 1494 (99\%) & 1496 (99\%) \\
\hline ACE inhibitors & $1383(92 \%)$ & $1384(91 \%)$ \\
\hline Angiotensin receptor antagonists & $94(6 \%)$ & $104(7 \%)$ \\
\hline Digitalis & $916(61 \%)$ & $884(58 \%)$ \\
\hline Antiarrhythmics & 189 (13\%) & $179(12 \%)$ \\
\hline Nitrates & $494(33 \%)$ & 498 (33\%) \\
\hline Aldosterone antagonists & $164(11 \%)$ & $163(11 \%)$ \\
\hline$\beta$ blockers $\ddagger$ & $64(4 \%)$ & $66(4 \%)$ \\
\hline Anticoagulants & $723(48 \%)$ & 662 (44\%) \\
\hline Aspirin & $528(35 \%)$ & 588 (39\%) \\
\hline Lipid lowering agents (statins) & $308(20 \%)$ & 331 (22\%) \\
\hline
\end{tabular}

NT-proBNP $=\mathrm{N}$-terminal probrain natriuretic peptide. $\mathrm{CAD}=$ coronary artery disease $\mathrm{CABG}=$ coronary artery bypass graft. $\mathrm{LBBB}=$ Left-bundle branch block.

$\mathrm{ACE}=$ angiotensin-converting enzyme. Data are mean (SD), median (range), or

number of patients (\%). *More than one answer possible. tInclusion criteria. $\ddagger$ Stopped before study start.

Table 1: Baseline characteristics

mortality difference. 1020 fatal events were needed to detect a risk reduction of $20 \%$ with at least $80 \%$ power. This calculation reflected the following: premature end of study treatment would reduce the anticipated risk reduction in mortality by $20 \%$, aggregate yearly mortality would be $8.1 \%$ and the overall type I error of 0.05 would be split- 0.04 for all-cause mortality and 0.01 for the composite endpoint. With respect to the composite endpoint, about 2400 events were expected, giving $80 \%$ power to detect a $15 \%$ reduction in risk at a significance level of 0.01 .

By the end of 2001, projections indicated that the required number of deaths would occur by November, 2002. The steering committee declared that all patients alive on Nov 15, 2002, would be administratively censored on that date for the purpose of all efficacy analyses. By that date 1112 patients had died.

Throughout the study, the data safety and monitoring board did regular reviews for efficacy and safety. Since use of $\beta$ blockers for heart failure was quite new at the start of the study, these reviews were scheduled for every 100 deaths. The protocol specified a fixed significance level of 0.0001 (Peto rule ${ }^{22}$ ) as a guideline for stopping the study at each interim analysis. However, the study finished as planned without early termination. Formally, the significance level for a comparison of treatments with respect to mortality must be less than 0.039 to ensure that the type I error for the study as a whole remains less than $0 \cdot 05$.

All randomised patients were included in the analysis of both efficacy and safety by the intention-to-treat principle. It was planned that all patients would be followed up to the end of the study, even after study treatment ended permanently. Some patients were lost to follow-up or withdrew consent. These patients were censored at the last known date of contact or date of withdrawal of consent, respectively.

We analysed the primary endpoints with a log-rank test without stratification. The relative risk (hazard ratio) and 95\% CI were estimated with a Cox's proportional hazard model with treatment as the only covariate. Sensitivity analyses to assess the robustness of the primary endpoint results accounted for the effect of additional baseline covariates and used a survival analysis with time-dependent covariates to assess the relative contribution of study treatments and any use of open-label $\beta$ blockade after previous end of study drugs.

Recorded survival times were well described by a statistical model that assumed a constant hazard in each treatment group (exponential survival). On this basis, standard maximum likelihood methods were used to obtain an estimate and a CI for the difference in median survival between the treatments.

\section{Role of the funding source}

The trial was designed, overseen, implemented, and assessed by an independent steering committee. Representatives of the sponsor attended meetings of the steering committee as non-voting members and in addition the independent members met separately. The study database is held by an independent data centre, the Nottingham Clinical Research Group, Nottingham, UK. The data centre was also responsible for statistical analysis of the data. Day to day operations were managed initially by Boehringer Mannheim and later by F Hoffmann La Roche.

\section{Results}

Of 3029 patients, $1511(50 \%)$ were assigned to treatment with carvedilol and $1518(50 \%)$ to metoprolol (figure 1). The mean study duration was 58 months (SD 6). Five patients were lost to follow-up and a further 28 patients withdrew their consent to further follow-up during the

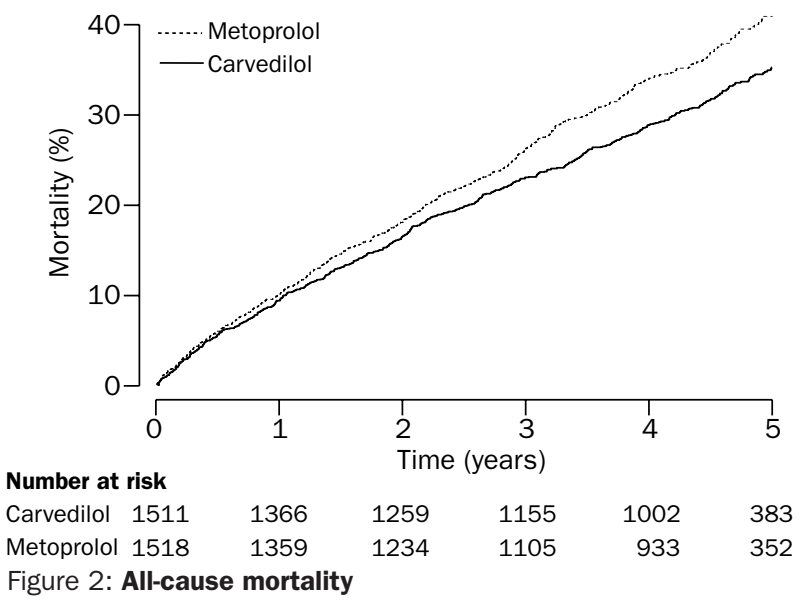




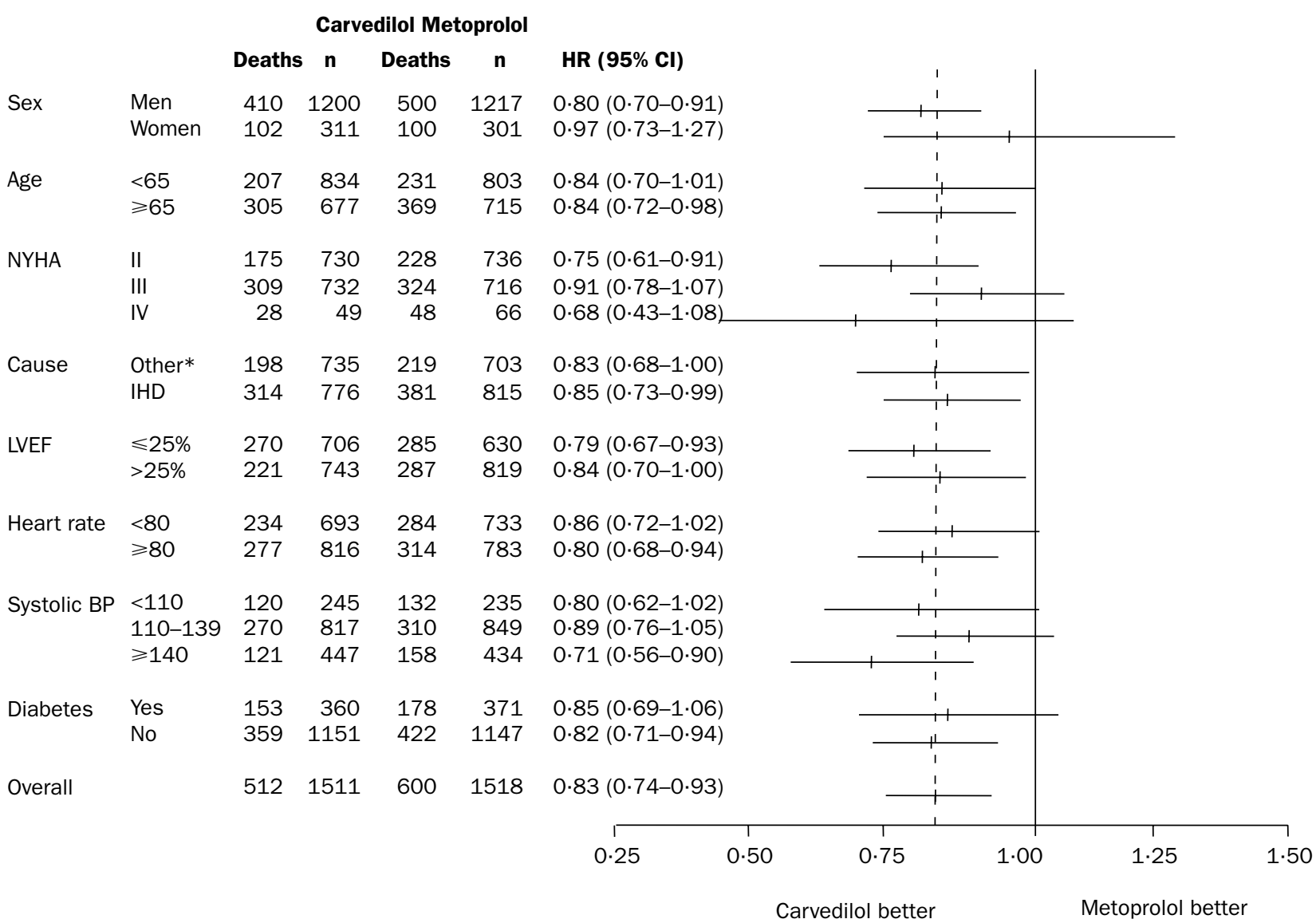

Figure 3: All-cause mortality by predefined subgroups

Points are hazard ratios (HR) and lines are 95\% CI. NYHA=New York Heart Association. IHD=ischaemic heart disease. LVEF=left-ventricular ejection fraction. $\mathrm{BP}=$ blood pressure.

course of the study. All other patients were followed up to death or study end.

Table 1 shows the baseline characteristics. The mean age was 62 years (11) and the mean ejection fraction $0 \cdot 26$ $(0 \cdot 07)$. Patients were evenly distributed between NYHA II and III.

Figure 2 shows the Kaplan-Meier estimates of all-cause mortality for each treatment. 512 people in the carvedilol group died compared with 600 in the metoprolol group, giving a hazard ratio of $0.83(95 \%$ CI $0.74-0.93$, $\mathrm{p}=0.0017)$ in favour of carvedilol. The mortality benefit became apparent at about 6 months. The reduction in all-cause mortality was similar in direction and in magnitude across the predefined subgroups (figure 3 ). In addition, sensitivity analyses confirmed the primary mortality analysis. The difference remained after adjustment for known prognostic factors. The on- treatment analysis showed a hazard ratio of 0.77 $(0 \cdot 67-0 \cdot 90, p=0 \cdot 0008)$ in favour of the carvedilol group. Although the number of deaths differed between groups, the distribution of mode of death was much the same for the two treatments. Sudden death was the adjudicated mode of death for 218 patients $(14 \%)$ in the carvedilol group and in $262(17 \%)$ patients in the metoprolol group$43 \%$ of all deaths in the carvedilol group and $44 \%$ in the metoprolol group. $33 \%$ of all deaths in both groups $(n=168$ for carvedilol and $n=197$ for metoprolol) were due to circulatory failure.

There were 438 cardiovascular deaths in the carvedilol group and 534 in the metoprololol group (table 2). 28 patients in the carvedilol group and 27 in the metoprolol group underwent heart transplantation.

1116 patients in the carvedilol group and 1160 in the metoprolol group died or were admitted (table 2). The

\begin{tabular}{|c|c|c|c|c|}
\hline & Carvedilol (n=1511) & Metoprolol ( $\mathrm{n=1518)}$ & Hazard ratio $(95 \% \mathrm{CI})$ & $\mathbf{p}$ \\
\hline All deaths & 512 (34\%) & $600(40 \%)$ & $0.83(0.74-0.93)$ & 0.002 \\
\hline 5 year Kaplan-Meier & $35 \cdot 3 \%$ & $41 \cdot 0 \%$ & $\cdot$. &.$\cdot$ \\
\hline Time at risk (months) & $46 \cdot 8(18.9)$ & $45 \cdot 2(19.5)$ & .. & $\cdot \cdot$ \\
\hline Yearly mortality rate & $8 \cdot 3$ & $10 \cdot 0$ & .. &.$\cdot$ \\
\hline Cardiovascular deaths & $438(29 \%)$ & $534(35 \%)$ & $0.80(0.70-0.90)$ & 0.0004 \\
\hline Non-cardiovascular deaths & $74(5 \%)$ & $66(4 \%)$ & $1.08(0.77-1.50)$ & .. \\
\hline All deaths and all-cause admission* & $1116(74 \%)$ & $1160(76 \%)$ & $0.94(0.86-1.02)$ & $0 \cdot 122$ \\
\hline 5 year Kaplan-Meier & $75 \cdot 5 \%$ & $78.5 \%$ &.$\cdot$ & $\cdot \cdot$ \\
\hline Time at risk (months) & $27 \cdot 1(22 \cdot 7)$ & $25 \cdot 9(22 \cdot 1)$ & .. &.$\cdot$ \\
\hline First event admission & $1022(68 \%)$ & $1031(68 \%)$ & .. &.$\cdot$ \\
\hline First event death & $94(6 \%)$ & 129 (8\%) & .. & .. \\
\hline
\end{tabular}

Data are number of deaths (\%) or mean (SD). *Any patient counted once only.

Table 2: Primary endpoints and components of the composite endpoint 


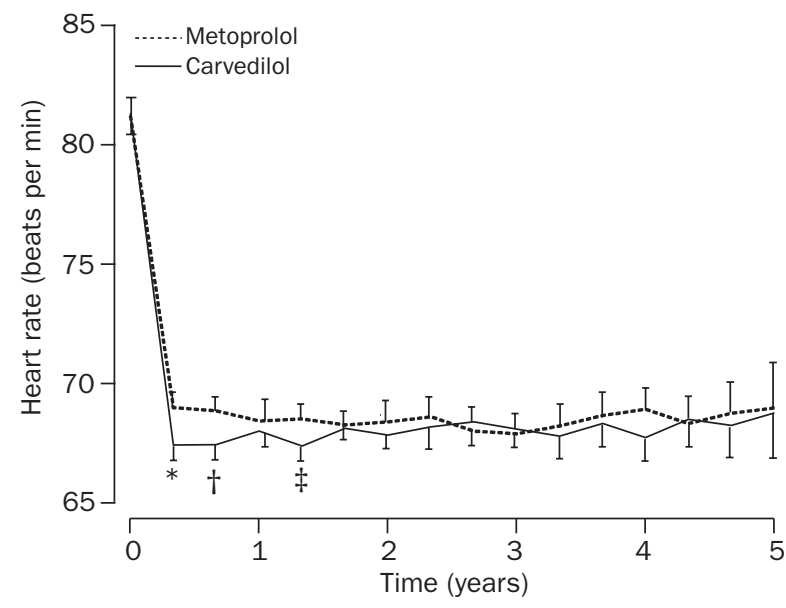

Figure 4: Heart rate at each visit on treatment

Error bars are $1 \mathrm{SE} . * p=0.0022 . \dagger p=0.0034 . \neq p=0.0040$.

hazard ratio for total admission alone was 0.97 (95\% CI $0 \cdot 89-1 \cdot 05, \mathrm{p}=0 \cdot 45)$ so that the composite endpoint was driven mainly by mortality.

The mean daily dose at entry into the maintenance phase in the carvedilol group $(\mathrm{n}=1308)$ was $41.8 \mathrm{mg}$ (SD 14.6) a day, with $1140(87 \%)$ patients taking $25 \mathrm{mg}$ a day or more, and $980(75 \%)$ receiving the target dose of $25 \mathrm{mg}$ twice a day. In the metoprolol group $(\mathrm{n}=1317)$ the mean daily dose was $85 \mathrm{mg}$ a day (SD 28.9), $1146(87 \%)$ taking $50 \mathrm{mg}$ a day or more, and $1019(78 \%)$ receiving the target dose of $50 \mathrm{mg}$ twice a day.

The mean baseline heart rates were identical (table 1). After 4 months of treatment, mean heart rate on treatment had decreased from baseline by 13.3 beats per min in the carvedilol group and by 11.7 beats per $\min$ in the metoprolol group (difference -1.6 beats per min, $95 \%$ CI $-2 \cdot 7$ to $-0 \cdot 6$ ). The change in heart rate for all patients over the period of the trial is shown in figure 4 . The heart rate did not differ after 16 months. At 4 months, patients mean decrease of systolic blood pressure from baseline was $3.8 \mathrm{~mm} \mathrm{Hg}(\mathrm{SD} \mathrm{17.4)}$ in the carvedilol group and $2.0 \mathrm{~mm} \mathrm{Hg}(\mathrm{SD} 17 \cdot 7)$ in the metoprolol group (difference $-1 \cdot 8 \mathrm{~mm} \mathrm{Hg}, 95 \% \mathrm{CI}-3 \cdot 2$ to $-0 \cdot 4$ ).

The study drug was permanently stopped for reasons other than death in 481 (32\%) patients in the carvedilol group and in $483(32 \%)$ in the metoprolol group. Reasons for permanent cessation of treatment were similar in the two groups, as were the distributions of time on treatment. In the carvedilol group $80.5 \%$ of the survival time was spent on the study drug, compared with $81.5 \%$ in the metoprolol group. The proportion of patients who had adverse events or serious adverse events and the number of events were fewer in the carvedilol group than the metoprolol group despite differences in mortality leading to a slightly longer mean observation time of $46 \cdot 8$ months

\begin{tabular}{|c|c|c|}
\hline & $\begin{array}{l}\text { Carvedilol } \\
(n=1511)\end{array}$ & $\begin{array}{l}\text { Metoprolol } \\
(n=1518)\end{array}$ \\
\hline Patients with at least one adverse event & $94 \%$ & $96 \%$ \\
\hline Number of adverse events & 8469 & 8808 \\
\hline $\begin{array}{l}\text { Patients with at least one cardiovascular adverse } \\
\text { event }\end{array}$ & $74 \%$ & $76 \%$ \\
\hline Number of cardiovascular events & 3529 & 3642 \\
\hline Patients with at least one serious adverse event & $75 \%$ & $77 \%$ \\
\hline Number of serious adverse events & 4035 & 4184 \\
\hline $\begin{array}{l}\text { Patients with at least one serious } \\
\text { cardiovascular adverse event }\end{array}$ & $55 \%$ & $57 \%$ \\
\hline Number of serious cardiovascular events & 2111 & 2265 \\
\hline
\end{tabular}

Values are number of patients (\%) or number of events.

Table 3: Safety variables
(SD 18.9) compared with 45.2 months (19.5) for metoprolol (tables 2 and 3 ). The pattern of adverse events usually associated with $\beta$ blockade was similar in the two groups. Bradycardia was reported in $144(10 \%)$ patients in the carvedilol group and in $135(9 \%)$ patients in the metoprolol group. Bradycardia was a serious adverse event in $3 \%$ of patients in both groups $(n=39$ with carvedilol and $\mathrm{n}=40$ with metoprolol). Hypotension was reported in 215 (14\%) patients in the carvedilol group and in 160 (11\%) patients in the metoprolol group. Hypotension was a serious adverse event in $48(3 \%)$ and in $29(2 \%)$ of patients, respectively.

\section{Discussion}

Our results suggest that carvedilol used for treatment of chronic heart failure, in patients optimally treated with diuretics and ACE inhibitors, has a significantly greater beneficial effect on survival than metoprolol. The absolute reduction in mortality over 5 years was $5 \cdot 7 \%$. Survival times were consistent with a constant hazard in each group permitting estimation of median survival. Extrapolation from the survival curves suggested that carvedilol extended median survival by 1.4 years $(95 \% \mathrm{CI}$ $0 \cdot 5-2 \cdot 3$ ) as compared with metoprolol (estimated median survival on carvedilol 8.0 years [95\% CI $7 \cdot 3-8 \cdot 7$ ], on metoprolol $6 \cdot 6$ years $[6 \cdot 1-7 \cdot 1])$. The calculated number of patient-years of treatment to save one life is $59,{ }^{23}$ which is similar to the effect of an ACE inhibitor or selective $\beta-1$ blocker versus placebo in comparable patient populations. The findings were consistent across predefined subgroups. Sensitivity analyses confirmed that the finding was robust and was not affected by variables such as the number of patients lost to follow-up or who withdrew consent. The patients included in the study had mild to severe heart failure (NYHA II-IV) and similar baseline characteristics to patients in earlier trials of $\beta$ blockers in heart failure. ${ }^{5,6}$ The yearly mortality rate was $8.3 \%$ for carvedilol and $10.0 \%$ for metoprolol. The yearly mortality rate in MERIT-HF ${ }^{6}$ was $7 \cdot 2 \%$ in the group given metoprolol, and in CIBIS- $\mathrm{II}^{5}$ the rate was $8.8 \%$ in the group given bisoprolol.

The composite endpoint of all-cause mortality and allcause admission, although numerically in favour of carvedilol, was not significant. Withdrawals from the trial, excluding death, were almost identical. It is uncommon in clinical trials to find no significant treatment difference with respect to a composite endpoint, but a clear difference in one component such as mortality. ${ }^{24}$ The benefit of carvedilol in this trial was thus driven by the reduction in mortality. The effect of carvedilol seems to be on a mechanism of death rather than on the determinants of admissions. The hazard reduction for cardiovascular mortality was $20 \%$.

$\beta$ blockers were first advocated for treatment of heart failure in $1975 .{ }^{25}$ Results of large clinical trials subsequently showed that carvedilol, ${ }^{4,7}$ metoprolol, ${ }^{6}$ and bisoprolol ${ }^{5}$ reduce mortality when added to conventional therapy. A trial with bucindolol ${ }^{13}$ was not successful. The $\beta$ blockers proven to be effective differ by their adrenergic receptor selectivity and their ancillary properties. The results of our study together with those of other studies showing varying degrees of benefit and harm indicate that these differences are important for clinical outcomes.

Results of several small studies have shown favourable effects of carvedilol compared with metoprolol in terms of haemodynamics but similar effects on quality of life. . $^{10,12,15-17}$ We began the trial in 1996 in response to the findings of earlier studies,,$^{4,26}$ but, during the course of the trial both of the drugs being compared had a favourable effect on mortality. ${ }^{6,7}$ 
In a large mortality study comparing two drugs, a decision has to be made about dose. The steering committee selected $25 \mathrm{mg}$ twice daily for carvedilol and 50 $\mathrm{mg}$ twice daily for metoprolol to be used as target doses in COMET to achieve a comparable degree of $\beta$ blockade in both groups. ${ }^{21}$ The evidence suggested that a dose ratio of 2 to 1 would achieve similar reductions in heart rate. In the Metoprolol Dilated Cardiomyopathy (MDC) trial2 ${ }^{26}$ the target dose for metoprolol was 100-150 mg daily. The actual mean dose was $108 \mathrm{mg}$ (SD 51) daily and the mean heart rate reduction was 15 beats per min. In the US carvedilol study ${ }^{4}$ the mean daily dose was $45 \mathrm{mg}$ (SD 27) and heart rate was reduced by 13 beats per min. The target dose of carvedilol in COPERNICUS was $25 \mathrm{mg}$ twice daily and the actual mean dose $37 \mathrm{mg}$ daily.

In 1988, Sandberg and colleagues ${ }^{27}$ compared a new multiple-unit, controlled release formulation of metoprolol, metoprolol succinate (metoprolol $\mathrm{CR} / \mathrm{XL}$ ), with the conventional metoprolol tartrate tablets in patients with heart failure and showed that the formulation showed a 30-35\% reduced systemic availability. When COMET was started, this preparation was not available to us. The target dose used in MERIT-HF (200 mg metoprolol succinate) is equivalent to about $130 \mathrm{mg}$ of the salt (metoprolol tartrate) used in COMET. In MERIT-HF the actual mean dose was $159 \mathrm{mg}$ once daily (equivalent to $106 \mathrm{mg}$ of metoprolol tartrate) and the reduction of heart rate 14 beats per min. In a post-hoc analysis of data from MERIT- $-\mathrm{HF}^{28}$ the risk reduction for mortality was identical in two groups analysed according to titrated dose $(\leqslant 100 \mathrm{mg}$ daily, and $>100 \mathrm{mg}$ daily), which achieved mean doses of metoprolol succinate of $76 \mathrm{mg}$ and $192 \mathrm{mg}$ once daily, respectively. These doses are equivalent to $51 \mathrm{mg}$ and $128 \mathrm{mg}$ metoprolol tartrate, respectively. The on-treatment reductions of heart rate were 14 beats per min and 16 beats per min, respectively at 3 months. In COMET the mean doses at the onset of the maintenance phase were for carvedilol $42 \mathrm{mg}$ daily and for metoprolol $85 \mathrm{mg}$ daily. The respective reductions of heart rate from an on-treatment analysis were 13.3 beats per min and 11.7 beats per min. After 16 months there were no differences (figure 4). In CIBIS $\mathrm{II}^{29}$ bisoprolol caused a mean reduction in heart rate of 10 beats per min at 2 months. The outcome of COMET is unlikely to be attributable to an effect of dose because of the comparability of the two doses as assessed from other studies, the flat dose-response to metoprolol in terms of heart rate and outcomes, ${ }^{28}$ and the similar reduction of heart rate in the two groups. The small differences in the fall of heart rate in the first 16 months of the trial do not necessarily indicate a different degree of $\beta$ blockade. The antagonistic effect of carvedilol on $\beta-2$ and $\alpha$-adrenergic receptors might have a discernible effect on heart rate and blood pressure. Clinical trials rarely establish a mechanism for any effect observed. The favourable outcome with carvedilol could be attributed to blockade of both $\beta-1$ and $\beta-2$ adrenergic receptors, inhibition of $\alpha$-adrenergic receptors, a greater anti-ischaemic effect, inhibition of apoptosis, an antioxidant action, free radical scavenging, or an electrophysiological effect.

Three $\beta$ blockers have been shown to confer benefit on patients with chronic heart failure. Metoprolol and bisoprolol are selective $\beta-1$ adrenergic receptor inhibitors. No previous comparisons of $\beta$ blocking drugs with different properties on long-term mortality and morbidity have been made in patients with heart failure. The results of this study show that carvedilol extends survival by comparison with metoprolol in patients with chronic heart failure.
COMET committee members

Steering committee

Philip A Poole-Wilson (UK, Chair), Karl Swedberg (Sweden, Deputy Chair), John G F Cleland (UK), Marco Metra (Italy), Peter Hanrath (Germany) Michel Komajda (France), Andrea Di Lenarda (Italy), Willem J Remme (Netherlands), Christian Torp-Pedersen (Denmark), and representatives of the sponsor

Data and safety monitoring committee

Jacobus Lubsen (Switzerland, Chair), Lars Wilhelmsen (Sweden), Hansjörg Just (Germany).

\section{Endpoint committee}

John G F Cleland (UK, Chair), Leif Erhardt (Sweden), Willem J Remme (Netherlands).

Independent data centre

The independent clinical trial data centre was the Nottingham Clinical Research Group (NCRG), Nottingham, UK. Samantha Stead (Data Management), Andrew Charlesworth (Statistics), Andrew Foxley (Project Management), Allan Skene (Director).

Investigators

Austria-D Brandt, H Drexler, G Gaul, D Geissler, F Hoppichler, W Klein, F Skrabal, T Stefenelli, F Stockenhuber, F Wilhelm, H Wimmer. Belgium-B Boland, G Boxho, J M Chaudron, J Creplet, D Duprez, R Geukens, J M Gregoire, V Hamoir, C Henuzet, C Laruelle, M Leonard, B Marchandise, J P Melchior, L Missault, C Philippart, B Van Frachen, J Vanwelden.

Denmark-A Dedingt, B Engby, T Glud, P Hildebrandt, J Markenvard, A Thomassen, C Torp-Pedersen, M Scheibel, H M Sejersen.

Finland-M Ikäheimo, P Kettunen, E Koskela, H Leinonen, J Lund, J Melin, A Palomäki, S Pohjola-Sintonen, U Rytkönen, K Soininen. France-O Abrieu, B Aleil, G Allard-Latour, J Armengaud, S Baleynaud, G Baradat, P Bareiss, J P Bertinchant, A Bieth, J B Bouhour, C Brandt, M Burdin, C Camier, C Caron, L Chartier, A Chassing, N Chedru, Y Chotard, L Christiaens, D Coisne, P Coulon, E Decoulx, P De Groote, B Delhoume, J M Demarcq, P Deshayes, R Dimitrou, B Discazeaux, S Doutreleau, P Duc, P Dugrand, J J Dujardin, X Dujardin, A Duval, B Estampes, J M Fournie, M Garcia, L Genet, N Guillard, G Habib, G Haddad, A A Hagege, R Heitz, V Hossler, A Julliard, Y Juilliere, R Lallemant, G Lande, L Ledain, H Le Marec, J Le Potier, F Leroy, J Lipiecki, J Loire, N Lucke, V Lucke, H Mann, X Marchand, M Nitel, M Pathé, A Pinzani, J P Preiss, F Raczka, J P Reboud, J Roncalli, B Rossignol, G J Roul, P Sultan, J N Trochu, Y Valy, A Verdun, A Wuillermin.

Germany-F-R Althoff, E Altmann, K Ammer, C Angermann, H J Arndt, W Bauer, K Bergmann, C Bergmeier, H Beyer, M Böhm, M M Borst, J Cyran, H Darius, H R Figulla, H J Frielitz, F Freytag, S Genth-Zotz, M G Gottwik, B Haaff, P Hanrath, F Hartmann, K E Hauptmann, H Herrmann, K Herrmann, J Hetzel, F Höltermann, C Holubarsch, R Hopf, T Horacek, A Jaeckle, E Jagodzinski, H U Klein, R K Klocke, B Krämer, P Kratochvil, J Krülls-Münch, H Landgraf, P Lenga, E Löffelholz, B Lösse, B Maisch, S Marbach, F Menzel, H P Nast, L Neyses, C Nienaber, J Nitsch, H Nordbeck, A Nötges, H H Osterhues, D Pfeiffer, F Richter, H Riedel, T Risler, F Saborowski, R Sack,

A Schärtel, A Schmidt, G Schmidt, G Schuler, P Schuster, R Schwinger, W Sehnert, H Sigel, R Simon, S Spitzer, H U K Stempfle, R Stöhring, R Strasser, M Theissen, O J Titlbach, H-J Trappe, M Trautnitz, R Uebis, W Urbaszek, W von Scheidt, C Weirich, C J Wick, M Wirth, J Wübbelt, M Zehender, R Zimmerman, R Zotz.

Hungary-L Cserhalmi, I Preda.

Italy-E Adornato, A Branzi, C Brunelli, M Clemente, S Coglitore,

L Dei Cas, A Perkan, F Fedele, C Fiorentini, S Forconi, G Gensini,

G Giuffrida, S Klugmann, M Mariani, G Mattioli, L Meloni, A Murrone, M Orlandi, S Pirelli, D Scrutinio, GP Trevi, B Tucillo, C Vassanelli, P Zonzin.

Netherlands-A H M M Balk, J C Chin, J H Cornel, M C G Daniels, M P Freericks, B J B Hamer, D P Hertzberger, G Hoedemaker, J C A Hoorntje, W Jaarsma, J H Kirkels, J A Kragten, C M Leenders, J A Lok, A H E M Maas, H R Michels, J R M Peters, P E Polak, J L Posma, S A M Said, L H Savalle, T B Tan, B J van den Berg, $\mathrm{L} H \mathrm{~J}$ van Kempen, $\mathrm{H}$ W Vliegen, A J A $M$ Withagen. Norway-K Dickstein, S Njålla, P K Rönnevik, B Wik. Portugal-F Ceia, R Ferreira, R Gonçalves, N Lousada, I Mendonça, L Providência, C Vagueiro. Spain-J Azpitarte Almagro,

F Fernández Avilés, E Galve Basilio, A Francino Batlle, A Castro Beiras, C Saenz de la Calzada, L Plaza Celemín, I Laynez Cerdeña,

J Burgos Cornejo, J Bruguera Cortada, L Saenz Cusí, L Martínez Elbal, A Llácer Escorihuela, E de Teresa Galvan, C Piñero Gálvez, C Ridao García, V López García-Aranda, F Sogorb Garri,

H Pérez Hernández, V Nieto Lago, J L Rodríguez Lambert, C Martín Luengo, J C Vargas Machuca, I González Maqueda, A Martínez, C Pallarés Monleón, I Ferreira Montero, J E Muñoz Moral, 
P Montes Orbe, L Rodríguez Padial, J A de Velasco Ramis,

J Beltrán Rodríguez, A Grande Ruiz, I Mínguez Enríquez de Salamanca, J M Aguirre Salcedo, J J Poveda Sierra, F Malpartida Torres, V Valle Tudela.

Sweden-G Agert, U Ahremark, M Ali, L Åström, K Boman, L Carmaciu-Aron, C Cline, C Dahlén, U Dahlström, S Ekdahl, J Ellström, G Gustafsson, C Höglund, J Jonsson, B Karlsson, T Kellerth, A Kierkegaard, L Klintberg, P Kvidal, O Lövheim, D Lundblad, B Malmros, E Mattsson, T Messner, B Möller, I Ödmansson, O Nilsson, E Pantev, F Rücker, A Stjerna, K Swedberg, S Thorsén, K Tolagen, B Ullman, C Wettervik, A Zingmark.

Switzerland-L Finci, A Gallino, T Moccetti, G Noll, P Vulliemin, K Weber.

UK-M N Al-Khafaji, J S Birkhead, A Brady, N H Brooks, J G F Cleland, P Das Gupta, J Dhawan, I N Findlay, B A Gould, I Hudson, P S Lewis, O Odemuyiwa, K G Oldroyd, D H Roberts, A Scriven, I B Squire, A D Timmis, T G Trouton, B D Vallance, P K Verma, S Walton.

\section{Conflict of interest statement}

P Poole-Wilson, K Swedberg, J Cleland, M Metra, P Hanrath, M Komajda, A Di Lenarda, W Remme, C Torp-Pedersen, and J Lubsen have served as consultants to or received travel expenses, payment for speaking at meetings or funding for research from one or more of the major pharmaceutical companies. Members of committees were funded to attend meetings relating to the trial.

\section{Acknowledgments}

We thank all the patients who participated in this trial and all the physicians and nurses whose work made the trial possible. The study was supported by F Hoffmann La Roche and GlaxoSmithKline.

\section{References}

1 Cowie MR, Mosterd A, Wood DA, et al. The epidemiology of heart failure. Eur Heart f 1997; 18: 208-25.

2 Remme WJ, Swedberg K. Guidelines for the diagnosis and treatment of chronic heart failure. Eur Heart f 2001; 22: 1527-60.

3 Garg R, Yusuf S. Overview of randomized trials of angiotensinconverting enzyme inhibitors on mortality and morbidity in patients with heart failure: collaborative Group on ACE Inhibitor Trials. fAMA 1995; 273: 1450-56.

4 Packer M, Bristow MR, Cohn JN, et al. The effect of carvedilol on morbidity and mortality in patients with chronic heart failure. N Engl f Med 1996; 334: 1349-55.

5 CIBIS-II Investigators and Committees. The Cardiac Insufficiency Bisoprolol Study II (CIBIS-II): a randomised trial. Lancet 1999; 353: 9-13

6 MERIT-HF Study Group. Effect of metoprolol CR/XL in chronic heart failure: Metoprolol CR/XL Randomised Intervention Trial in Congestive Heart Failure (MERIT-HF). Lancet 1999; 353: 2001-07.

7 Packer M, Coats AJ, Fowler MB, et al. Effect of carvedilol on survival in severe chronic heart failure. N Engl f Med 2001; 344: 1651-58.

8 Shibata MC, Flather MD, Wang D. Systematic review of the impact of beta blockers on mortality and hospital admissions in heart failure. Eur f Heart Fail 2001; 3: 351-57.

9 Hjalmarson A, Goldstein S, Fagerberg B, et al. Effects of controlledrelease metoprolol on total mortality, hospitalizations, and well-being in patients with heart failure: the Metoprolol CR/XL Randomized Intervention Trial in congestive heart failure (MERIT-HF). MERITHF Study Group. fAMA 2000; 283: 1295-302.

10 Bolger AP, Al-Nasser F. Beta-blockers for chronic heart fialure: surviving longer but feeling better? Int $\mathcal{F}$ Cardiol. Available from www.sciencedirect.com/science/jpurnal/01675273 (accessed June 10, 2003).

11 Australia/New Zealand heart failure research collaborative group. Randomised, placebo-controlled trial of carvedilol in patients with congestive heart failure due to ischaemic heart disease. Lancet 1997 349: $375-80$.

12 Gilbert EM, Abraham WT, Olsen S, et al. Comparative hemodynamic, left ventricular functional, and antiadrenergic effects of chronic treatment with metoprolol versus carvedilol in the failing heart. Circulation 1996; 94: 2817-25.

13 The Beta-Blocker Evaluation of Survival Trial Investigators. A trial of the beta-blocker bucindolol in patients with advanced chronic heart failure. N Engl f Med 2001; 344: 1659-67.

14 Packer M, Antonopoulos GV, Berlin JA, Chittams J, Konstam MA, Udelson JE. Comparative effects of carvedilol and metoprolol on left ventricular ejection fraction in heart failure: results of a meta-analysis. Am Heart f 2001; 141: 899-907.

15 Di Lenarda A, Sabbadini G, Salvatore L, et al. Long-term effects of carvedilol in idiopathic dilated cardiomyopathy with persistent left ventricular dysfunction despite chronic metoprolol. The Heart-Muscle Disease Study Group. 7 Am Coll Cardiol 1999; 33: 1926-34.

16 Metra M, Giubbini R, Nodari S, Boldi E, Modena MG, Dei CL. Differential effects of beta-blockers in patients with heart failure: a prospective, randomized, double-blind comparison of the longterm effects of metoprolol versus carvedilol. Circulation 2000; 102: 546-51.

17 Sanderson JE, Chan SKW, Yip G, et al. Beta-blockade in heart failure: a comparison of carvedilol with metoprolol. $f \mathrm{Am}$ Coll Cardiol 1999; 34: 1522-28.

18 Jacob S, Rett K, Wicklmayr M, Agrawal B, Augustin HJ, Dietze GJ. Differential effect of chronic treatment with two beta-blocking agents on insulin sensitivity: the carvedilol-metoprolol study. $\mathcal{F}$ Hypertens 1996; 14: 489-94.

19 Yue TL, Cheng HY, Lysko PG, et al. Carvedilol, a new vasodilato and beta adrenoceptor antagonist, is an antioxidant and free radical scavenger. F Pharmacol Exp Ther 1992; 263: 92-98.

20 Rossig L, Haendeler J, Mallat Z, et al. Congestive heart failure induces endothelial cell apoptosis: protective role of carvedilol. f Am Coll Cardiol 2000; 36: 2081-89.

21 Poole-Wilson PA, Cleland JG, Di Lenarda A, et al. Rationale and design of the carvedilol or metoprolol European trial in patients with chronic heart failure: COMET. Eur F Heart Fail 2002; 4: 321-29.

22 Peto R, Pike MC, Armitage P, et al. Design and analysis of randomized clinical trials requiring prolonged observation of each patient. I. Introduction and design. Br f Cancer 1976; 34: 585-612.

23 Lubsen J, Hoes A, Grobbee D. Implications of trial results: the potentially misleading notions of number needed to treat and average duration of life gained. Lancet 2000; 356: 1757-59.

24 Freemantle N, Calvert M, Wood J, Eastaugh J, Griffin C. Composite outcomes in randomized trials: greater precision but with greater uncertainty? ҰAMA 2003; 289: 2554-59.

25 Waagstein F, Hjalmarson A, Varnauskas E, Wallentin I. Effect of chronic beta-adrenergic receptor blockade in congestive cardiomyopathy. Br Heart f 1975; 37: 1022-36.

26 Waagstein F, Bristow MR, Swedberg K, et al. Beneficial effects of metoprolol in idiopathic dilated cardiomyopathy. Lancet 1993; 342: 1441-46.

27 Sandberg A, Blomqvist I, Jonsson UE, Lundborg P. Pharmacokinetic and pharmacodynamic properties of a new controlled-release formulation of metoprolol: a comparison with conventional tablets. Eur 7 Clin Pharmacol 1988; 33 (suppl): S9-14.

28 Wikstrand J, Hjalmarson A, Waagstein F, et al. Dose of metoprolol $\mathrm{CR} / \mathrm{XL}$ and clinical outcomes in patients with heart failure: analysis of the experience in metoprolol $\mathrm{CR} / \mathrm{XL}$ randomized intervention trial in chronic heart failure (MERIT-HF). f Am Coll Cardiol 2002; 40: 491-98.

29 Lechat P, Hulot JS, Escolano S, et al. Heart rate and cardiac rhythm relationships with bisoprolol benefit in chronic heart failure in CIBIS II Trial. Circulation 2001; 103: 1428-33. 